\title{
Study of Structural and Optical Properties of Zinc Oxide Rods Grown on Glasses by Chemical Spray Pyrolysis
}

\author{
Erdal Sonmez, ${ }^{1}$ Serdar Aydin,, ${ }^{1}$ Mehmet Yilmaz, $^{1}$ Mustafa Tolga Yurtcan, ${ }^{1}$ Tevhit Karacali, ${ }^{2}$ \\ and Mehmet Ertugrul ${ }^{2}$
}

${ }^{1}$ Physics Department, Education Faculty, University of Atatürk, 25240 Erzurum, Turkey
${ }^{2}$ Electrical and Electronics Engineering Department, University of Atatürk, 25240 Erzurum, Turkey

Correspondence should be addressed to Erdal Sonmez, esonmez@atauni.edu.tr

Received 29 March 2011; Accepted 11 April 2011

Academic Editor: Ting Zhu

Copyright (C) 2012 Erdal Sonmez et al. This is an open access article distributed under the Creative Commons Attribution License, which permits unrestricted use, distribution, and reproduction in any medium, provided the original work is properly cited.

We have investigated morphological and optical properties of zinc oxide rods. Highly structured ZnO layers comprising with wellshaped hexagonal rods were prepared by spray pyrolysis deposition of zinc chloride aqueous solutions at $\sim 550^{\circ} \mathrm{C}$. The rods were characterized by X-ray diffraction, scanning electron microscopy, atomic force microscopy, photoluminescence, and ultraviolet and visible absorption spectroscopy measurements. The deposition of the $0.1 \mathrm{~mol} / \mathrm{L}$ solution at $\sim 550^{\circ} \mathrm{C}$ resulted in crystals with a diameter of $400-1000 \mathrm{~nm}$ and length of $500-2000 \mathrm{~nm}$. Sharp near-band edge emission peaks, centered at 3844 and $3680 \AA$, dominated the PL spectra of $\mathrm{ZnO}$ at $300 \mathrm{~K}$ and $6.2 \mathrm{~K}$, respectively. In addition to this, absorption coefficient was determined by absorption measurement. X-ray diffraction, scanning electron microscopy and atomic force microscopy, results suggest that ZnO rods, prepared by spray pyrolysis, have high crystalline quality. This is desirable in nanotechnology applications.

\section{Introduction}

Zinc oxide $(\mathrm{ZnO})$ is a commercially important material utilized in paints, rubber, catalysts, sensors, varistors, and so forth. $\mathrm{ZnO}$ exhibits semiconducting, piezoelectric, and pyroelectric properties $[1,2]$. Nanostructured $\mathrm{ZnO}$ has a potential for application in nanotechnology [3, 4]. Structural, morphological, optical, and electrical properties of $\mathrm{ZnO}$ can be changed drastically by its doping with various metal cations [5]. Furthermore, $\mathrm{ZnO}$ thin films have recently been studied as an active channel material in thin film transistors [6, 7]. Chemically, $\mathrm{ZnO}$ is a simple compound; morphologically, however, this material is very rich in terms of the geometry of its particles. Many researchers focused on the investigation of the relationship between the synthesis route of $\mathrm{ZnO}$ on one side, due to their large exciton binding energy of $\sim 60 \mathrm{meV}$ at room temperature [8-13]. $\mathrm{ZnO}$ particles were largely prepared by using "wet" chemistry or pyrolysis, whereas the vacuum techniques prevailed in making thin $\mathrm{ZnO}$ films. The starting zinc compound, chemical composition of solvent, nature of the precipitating agent, $\mathrm{pH}$, temperature, and time of aging influence the size and geometrical shape of $\mathrm{ZnO}$ particles [14].
In the past years, the $\mathrm{ZnO}$ micro/nanostructures with different shapes were synthesized by various approaches reported by many research groups. These methods include chemical vapor transport and condensation $[15,16]$, thermal evaporation [17], metal organic chemical vapor deposition [18], hydrothermal method [19], sol-gel method [20, $21]$, electrochemical deposition $[22,23]$, ion beam-assisted deposition [24], laser ablation [25], and sputter deposition [26].

In this study, $\mathrm{ZnO}$ rods were prepared by chemical spray pyrolysis technique. The spray pyrolysis is an attractive method to obtain thin films, since it has been proved to be a simple and inexpensive method and it is particularly useful for large area of nanotechnology applications. In addition, chemical spray pyrolysis has the advantage over the other methods in that it does not consume much time and is a costeffective, catalyst, and template-free method to prepare $\mathrm{ZnO}$ nanostructures. Here, we report the direct growth of zinc oxide rods on glass substrate [27-30] by a chemical spray pyrolysis method. We have also studied the structural, morphological, and optical properties of the films with the aim of understanding physical properties of the obtained $\mathrm{ZnO}$ rods. 


\section{Experimental}

$\mathrm{ZnO}$ rods were grown by a chemical spray pyrolysis technique. The spray solution was prepared dissolving $\mathrm{ZnCl}_{2}$ $(2.7256 \mathrm{~g})$ in $200 \mathrm{~mL}$ distilled water. The initial $\mathrm{pH}$ value of solution was measured as 6 . The starting solution was atomized at a frequency of $1.63 \mathrm{MHz}$ by an ultrasonic nebulizer and by using dry air. The solution was mixed with magnetic mixer. Mixing process lasted for $30 \mathrm{~min}$. The nozzle-substrate distance was maintained at $10 \mathrm{~cm}$ with 45 degree, and the substrate temperature was fixed at $\sim 550^{\circ} \mathrm{C}$ by TET-612 temperature controller device on the metallic hot plate surface, because a flat $\mathrm{ZnO}$ film evolves into the the structured layer consisting of single-crystalline hexagonal elongated prims at growth temperatures close to $\sim 500^{\circ} \mathrm{C}$ and above [27]. The temperature of the metallic plate surface was totally stable. The substrates are normal microscope glasses which were cut with the dimensions of $10 \times 10$ $\times 1 \mathrm{~mm}$. Before loading into the system, the substrates were washed with detergent and then completely rinsed in methanol, acetone, and deionized water, respectively, and dried in air. Then, the substrates were progressively heated up to the required temperature, before being sprayed on. At this temperature, it was observed that the glass substrate became soft. The 5-6 $\mu \mathrm{m}$ diameter droplets were carried onto heated glass substrates. The flow rate of air used as a carrier gas was $2 \mathrm{~mL} / \mathrm{min}$. The duration of the film deposition was about $100 \mathrm{~min}$. The colour of $\mathrm{ZnO}$ film was white, and it had very good adhesion to glass substrates. The structural characterization of the films was carried out by Xray diffraction (XRD) measurements using a Rigaku D/MaxIIIC diffractometer with CuK $\alpha 1$ radiation $(\lambda=1.5418 \AA)$, at $30 \mathrm{kV}, 10 \mathrm{~mA}$. Surface morphology was examined by a JEOL JSM5610 model scanning electron microscope operating at $24 \mathrm{kV}$. The diameter and length of the rods were measured by a scanning electron microscope (SEM). In addition, morphology was also determined by atomic force microscopy (AFM). The optical characterization of the films was carried out by photoluminescence (PL) with an $\mathrm{He}-\mathrm{Cd}$ ion laser as a light source using an excitation wavelength of $325 \mathrm{~nm}$. So absorption coefficient was determined by UVVIS absorption (UV) spectroscopy measurement.

\section{Result and Discussion}

3.1. Structural Properties. XRD patterns of the grown $\mathrm{ZnO}$ samples are shown in Figure 1. The diffraction pattern of grown sample shows a peak corresponding to (002) planereflection together with highly diminished peaks corresponding to other planes of wurtzite $\mathrm{ZnO}$ structure. The high intensity of (002) plane as compared with other planes clearly suggests the preferential growth of rods along the $c$-axis direction. The XRD pattern shows increase in the intensities of peaks due to reflections from all crystallographic planes of (100), (002), (101), (102), and (110) of wurtzite $\mathrm{ZnO}$ structure with predominant counts for (002) plane.

Taking SEM and AFM into consideration, we see that $\mathrm{ZnO}$ structures are spreading uniformly onto the sample surface, and vertically increasing from the axis $\mathrm{c}$ in Figures

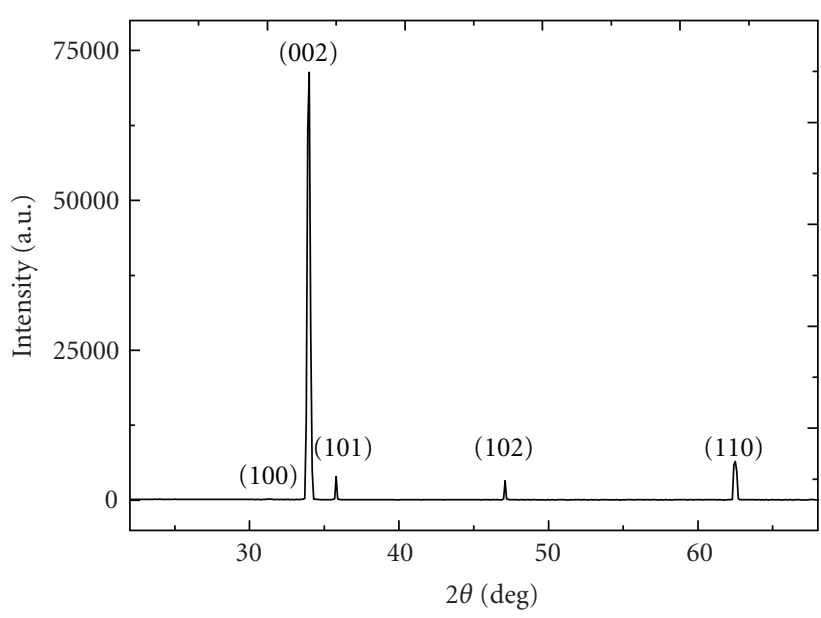

FIGURE 1: XRD pattern of $\mathrm{ZnO}$ rods deposited on glass substrate.

2 and 3. The length of the $\mathrm{ZnO}$ rods is between 500 and $2000 \mathrm{~nm}$, and the diameter changes between 400 and $1000 \mathrm{~nm}$. The diameter and length of the $\mathrm{ZnO}$ rods acquired by SEM were confirmed by graphs acquired by means of AFM. These cross-section graphics are important that the same length or diameter is achieved on the plane sample. AFM results are in compliance with the SEM investigation. Additionally, the reason of the sunflower-like structures in the SEM pictures is unknown, but we thought that the reason of these structures may be related to the temperature gradient on the glass substrates (Figure 2(b)).

3.2. Optical Properties. Figure 4(a) was acquired from the room temperature PL spectra of the synthesized $\mathrm{ZnO}$ rods. Two peaks are observed in this figure: exciton peak in the left side and donor-acceptor peak in the right side. Figure 4(b) was acquired from the cryogenic PL spectra. Two peaks are observed in the spectrum at $6.2 \mathrm{~K}$ : one is a strong, dominated, and high-intensity peak at $3680 \AA$ in the UV region; the other is a suppressed and week band at $5500 \AA$ in the visible region.

The UV emission is also called as near-band edge emission and originated by the recombination of the free excitons. The green band in the visible region, known as deep level emission, is generally explained by the radiative recombination of the photo-generated hole with the electrons which belong to ionized oxygen vacancies [31]. In our case, the UV emission is dominated over the green level emission. The weak peak is a result of donor acceptor pairs (DAPs) which can cause emission at room temperature. These DAPs are made up of dislocations or impurity in crystal. In general, the UV peak at room temperature is attributed to near band-edge (NBE) free exciton transition from the localized level below the conduction band to the valance band [32]. The emissions which are produced by DAP are decreasing by the temperature decrease because activity is decreasing by the temperature. The sharply peak is made up of exciton doublets which are not decomposed at the room temperature. According to PL data which is obtained in $6.2 \mathrm{~K}$, the sharp peaks' duration increases at 


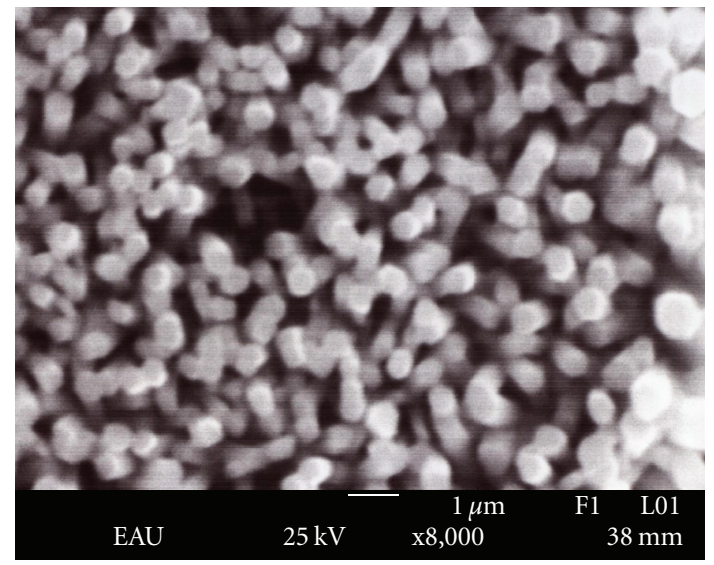

(a)

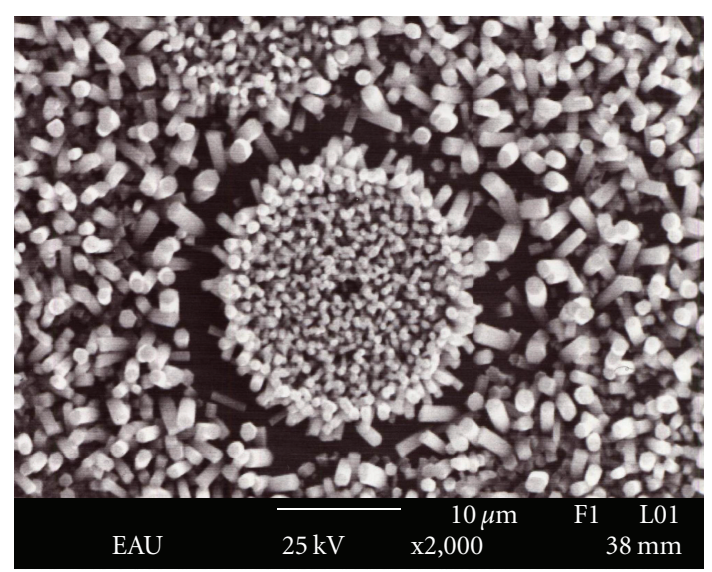

(b)

Figure 2: SEM images of $\mathrm{ZnO}$ rods. (a) Hexagonal $\mathrm{ZnO}$ nanorods. (b) The result from temperature gradient-dependent structure deformation.

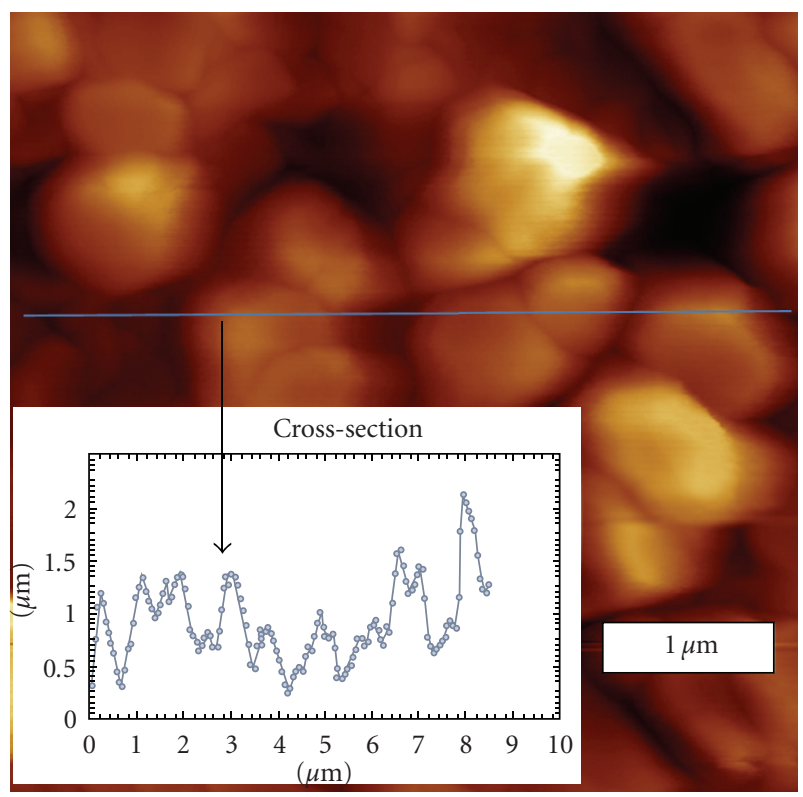

FIgURE 3: AFM image and cross-section graphic of the $\mathrm{ZnO}$ rods.

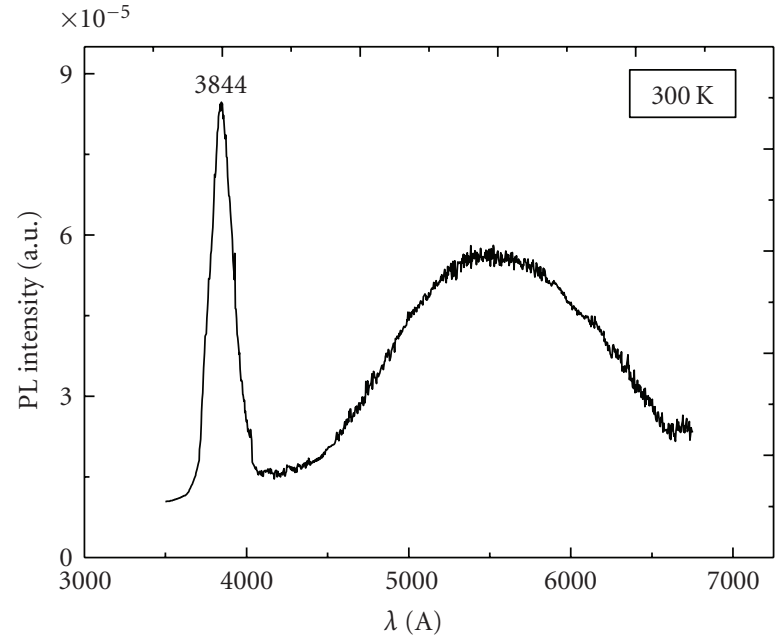

(a)

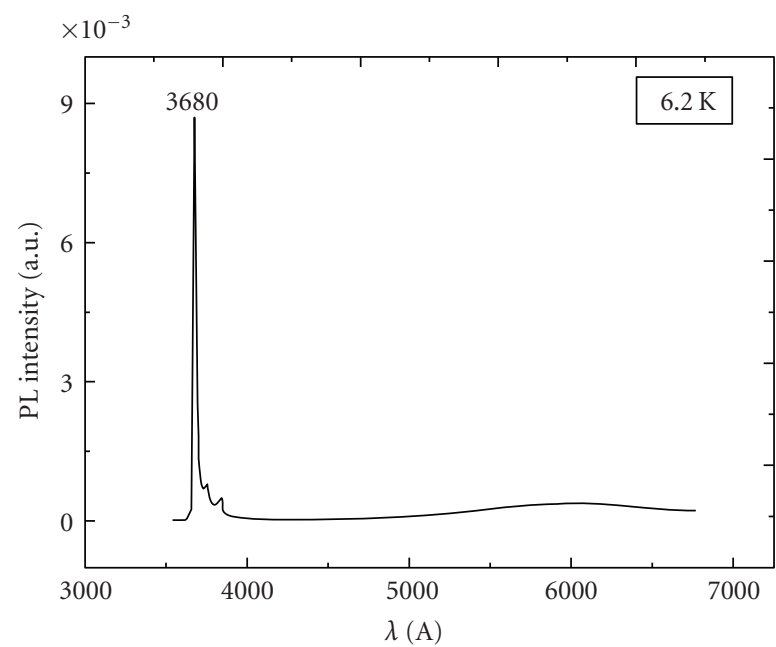

(b)

Figure 4: PL spectra of $\mathrm{ZnO}$ rods at (a) $300 \mathrm{~K}$ and (b) $6.2 \mathrm{~K}$.

temperature decrease, so peak intensity increases and slides to the left side because decrement of temperature widens the band gap. The other peak seems like decreasing because of the increase of sharp peaks' intensity. It has been reported that the improvement in the crystal quality such as low structural defects, oxygen vacancies, zinc interstitials, and decrease in the impurities may cause the appearance of a sharp and strong UV emission and a suppressed and weak green emission [33]. So the presence of a strong UV emission and a weak green emission from the synthesized $\mathrm{ZnO}$ rods indicated that the grown structures have good crystal quality with less structural defects [34]. The absorption coefficient is one of the intrinsic parameters of the $\mathrm{ZnO}$ rods that was determined by fitting the absorption spectrum with an appropriate Beer-Lambert Law. The thickness of the $\mathrm{ZnO}$ rods was verified by the cross-section graphic of the AFM (Figure 3) and SEM images (Figure 2). The value of the energy and absorption coefficient calculation was carried out for the $\mathrm{ZnO}$ rods. It was found that the value of the energy is 
$3.35 \mathrm{eV}$ and the absorption coefficient is $145125 \mathrm{~cm}^{-1}$ for the largest peak.

\section{Conclusion}

In this study, the $\mathrm{ZnO}$ rods on glass substrate were obtained by the ultrasonic spray pyrolysis method. The microstructures of $\mathrm{ZnO}$ rods were characterized by SEM, AFM images, and XRD patterns. Optical properties were obtained by PL spectrometer and UV-Vis measurements. Sharp nearband edge (NBE) emission peaks centered at 3844 and $3680 \AA$ dominated the PL spectra of $\mathrm{ZnO}$ at $300 \mathrm{~K}$ and $6.2 \mathrm{~K}$, respectively. In addition, structural analysis showed that the rods are $c$-axis-orientated $\mathrm{ZnO}$ wurzite crystals. The $\mathrm{ZnO}$ rods produced at optimum substrate temperature of $\sim 550^{\circ} \mathrm{C}$ exhibited single phase of $\mathrm{ZnO}$ with preferred (002) orientation. Diameter and length of size $\mathrm{ZnO}$ rods were 500-2000 and $4002000 \mathrm{~nm}$, respectively. It was found that $\mathrm{ZnO}$ rods with good structural and morphological properties can be produced on glass. These results indicate that spray pyrolysis methods are a viable technique for producing highquality $\mathrm{ZnO}$ rods for optical devices. At the same time, it is important to discuss the implementation of the presented results in this study for optoelectronic applications. The main issue in nanotechnology is to get devices in small size. The present work will contribute to the understanding of related photoluminescence, optical, structural, and morphological properties of $\mathrm{ZnO}$ nanomaterials.

\section{References}

[1] Z. L. Wang, "Nanostructures of zinc oxide," Materials Today, vol. 7, no. 6, pp. 26-33, 2004.

[2] N. Tamaekong, C. Liewhiran, A. Wisitsoraat, and S. Phanichphant, "Flame-spray-made undoped zinc oxide films for gas sensing applications," Sensors, vol. 10, no. 8, pp. 7863-7873, 2010.

[3] Y. H. Heo, D. P. Norton, L. C. Tien et al., "Low temperature $\left(<100^{\circ} \mathrm{C}\right)$ patterned growth of $\mathrm{ZnO}$ nanorod arrays on $\mathrm{Si}$," Materials Science and Engineering R-Reports, vol. 47, no. 1-2, pp. 1-47, 2004.

[4] M. J. Height, L. Madler, S. E. Pratsinis, and F. Krumeich, "Nanorods of $\mathrm{ZnO}$ made by flame spray pyrolysis," Chemistry of Materials, vol. 18, no. 2, pp. 572-578, 2006.

[5] D. P. Norton, Y. W. Heo, M. P. Ivill et al., "ZnO: growth, doping \& processing," Materials Today, vol. 7, no. 6, pp. 34-40, 2004.

[6] E. Fortunato, P. Barquinha, A. Pimentel et al., "Recent advances in $\mathrm{ZnO}$ transparent thin film transistors," Thin Solid Films, vol. 487, no. 1-2, pp. 205-211, 2005.

[7] E. Fortunato, P. Barquinha, A. Pimentel et al., "Fully transparent $\mathrm{ZnO}$ thin-film transistor produced at room temperature," Advanced Materials, vol. 17, no. 5, pp. 590-594, 2005.

[8] S. Choopun, R. D. Vispute, W. Noch et al., "Oxygen pressuretuned epitaxy and optoelectronic properties of laser-deposited ZnO films on sapphire," Applied Physics Letters, vol. 75, no. 25, pp. 3947-3949, 1999.

[9] Y. Li, G. W. Meng, L. D. Zhang, and F. Phillipp, “Ordered semiconductor $\mathrm{ZnO}$ nanowire arrays and their photoluminescence properties," Applied Physics Letters, vol. 76, no. 15, pp. 20112014, 2000.
[10] L. Guo, S. Yang, C. Yang et al., "Highly monodisperse polymer-capped $\mathrm{ZnO}$ nanoparticles: preparation and optical properties," Applied Physics Letters, vol. 76, no. 20, pp. 2901-2903, 2000.

[11] R. Wu, C. Xie, H. Xia, J. Hu, and A. Wang, "The thermal physical formation of $\mathrm{ZnO}$ nanoparticles and their morphology," Journal of Crystal Growth, vol. 217, no. 3, pp. 274-280, 2000.

[12] Y. Lia, X. L. Chen, H. Li, M. He, and Z. Y. Qiao, "Fabrication of zinc oxide nanorods," Journal of Crystal Growth, vol. 233, no. 1-2, pp. 5-7, 2001.

[13] B. K. Meyer, H. Alves, D. M. Hofmann et al., "Bound excition and donor-acceptor pair recombination ZnO," Physica Status Solidi B, vol. 241, no. 2, pp. 231-260, 2004.

[14] S. Music, A. Saric, and S. Popovic, "Dependence of the microstructural properties of $\mathrm{ZnO}$ particles on their synthesis," Journal of Alloys and Compounds, vol. 448, no. 1-2, pp. 277-283, 2008.

[15] K. Keis, E. Magnusson, H. Lindstrom, S. E. Lindquist, and A. Hagfeldt, "A 5\% efficient photoelectrochemical solar cell based on nanostructured $\mathrm{ZnO}$ electrodes," Solar Energy Materials and Solar Cells, vol. 73, no. 1, pp. 51-58, 2002.

[16] D. Voss, "Condensed-matter physics: switch-hitter materials tantalize theorists," Science, vol. 292, no. 5524, pp. 1987-1990, 2001.

[17] M. H. Huang, Y. Wu, H. Feick, N. Tran, E. Weber, and P. Yang, "Catalytic growth of zinc oxide nanowires by vapor transport," Advanced Materials, vol. 13, no. 2, pp. 113-116, 2001.

[18] W. Lee, M. C. Jeong, and J. M. Myoung, "Catalyst-free growth of $\mathrm{ZnO}$ nanowires by metal-organic chemical vapour deposition (MOCVD) and thermal evaporation," Acta Materialia, vol. 52, no. 13, pp. 3949-3957, 2004.

[19] Z. R. Dai, Z. W. Pan, and Z. L. Wang, "Novel nanostructures of functional oxides synthesized by thermal evaporation," Advanced Functional Materials, vol. 13, no. 1, pp. 9-24, 2003.

[20] L. E. Greene, M. Law, J. Goldberger et al., "Low-temperature wafer-scale production of $\mathrm{ZnO}$ nanowire arrays," Angewandte Chemie-International Edition, vol. 42, no. 26, pp. 3031-3034, 2003.

[21] S. E. Ahn, J. S. Lee, H. Kim et al., "Photoresponse of sol-gelsynthesized ZnO nanorods," Applied Physics Letters, vol. 84, no. 975, pp. 5022-5024, 2004.

[22] Y. C. Wang and M. H. Hon, "Preparation of nanosized $\mathrm{ZnO}$ arrays by electrophoretic deposition," Electrochemical and Solid-State Letters, vol. 5, no. 4, pp. C53-C55, 2002.

[23] M. J. Zheng, "Fabrication and optical properties of large-scale uniform zinc oxide nanowire arrays by one-step electrochemical deposition technique," Chemical Physics Letters, vol. 363, no. 1-2, pp. 123-128, 2002.

[24] W. Li, D. S. Mao, Z. H. Zheng et al., "ZnO/Zn phosphor thin films prepared by IBED," Surface and Coatings Technology, vol. 128-129, no. 1, pp. 346-350, 2000.

[25] Y. Sun, G. M. Fuge, and M. N. R. Ashfold, " $\mathrm{ZnO} / \mathrm{Zn}$ phosphor thin films prepared by IBED," Chemical Physics Letters, vol. 396, no. 1-3, pp. 21-26, 2004.

[26] W. Chiou, W. Wu, and J. Ting, "Growth of single crystal $\mathrm{ZnO}$ nanowires using sputter deposition," Diamond and Related Materials, vol. 12, no. 10-11, pp. 1841-1844, 2003.

[27] U. Alver, T. Kilinc, E. Bacaksiz et al., "Synthesis and characterization of spray pyrolysis Zinc Oxide microrods," Thin Solid Films, vol. 515, no. 7-8, pp. 3448-3451, 2007.

[28] V. V. Kireev, L. N. Dem'yanets, L. E. Li, and V. V. Artemov, "Growth of thin $\mathrm{ZnO}$ films by ultrasonic spray pyrolysis," Inorganic Materials, vol. 46, no. 2, pp. 154-162, 2010. 
[29] A. Khoury, R. al Asmar, M. Abdallah, G. El Hajj Moussa, and A. Foucaran, "Comparative study between zinc oxide elaborated by spray pyrolysis, electron beam evaporation and rf magnetron techniques," Physica Status Solidi A, vol. 207, no. 8, pp. 1900-1904, 2010.

[30] Z. L. Wang, "Zinc oxide nanostructures: growth, properties and applications," Journal of Physics Condensed Matter, vol. 16, no. 16, pp. R829-R858, 2004.

[31] K. Vanheusden, C. H. Seager, W. L. Warren, D. R. Tallant, and J. A. Voigt, "Mechanisms behind green photoluminescence in ZnO phosphor powders," Journal of Applied Physics, vol. 79, no. 10, pp. 7983-7990, 1996.

[32] S. Cho, J. Ma, Y. Kim, Y. Sun, G. K. L. Wong, and J. B. Ketterson, "Photoluminescence and ultraviolet lasing of polycrystalline $\mathrm{ZnO}$ thin films prepared by the oxidation of the metallic Zn," Applied Physics Letters, vol. 75, no. 18, pp. 2761-2763, 1999.

[33] D. M. Bagnall, Y. F. Chen, Z. Zhu, T. Yao, M. Y. Shen, and T. Goto, "High temperature excitonic stimulated emission from ZnO epitaxial layers," Applied Physics Letters, vol. 73, no. 8, pp. 1038-1042, 1998.

[34] A. Umar, S. H. Kim, Y.-S. Lee, K. S. Nahm, and Y. B. Hahn, "Catalyst-free large-quantity synthesis of $\mathrm{ZnO}$ nanorods by a vapor-solid growth mechanism: structural and optical properties," Journal of Crystal Growth, vol. 282, no. 1-2, pp. 131-136, 2005. 

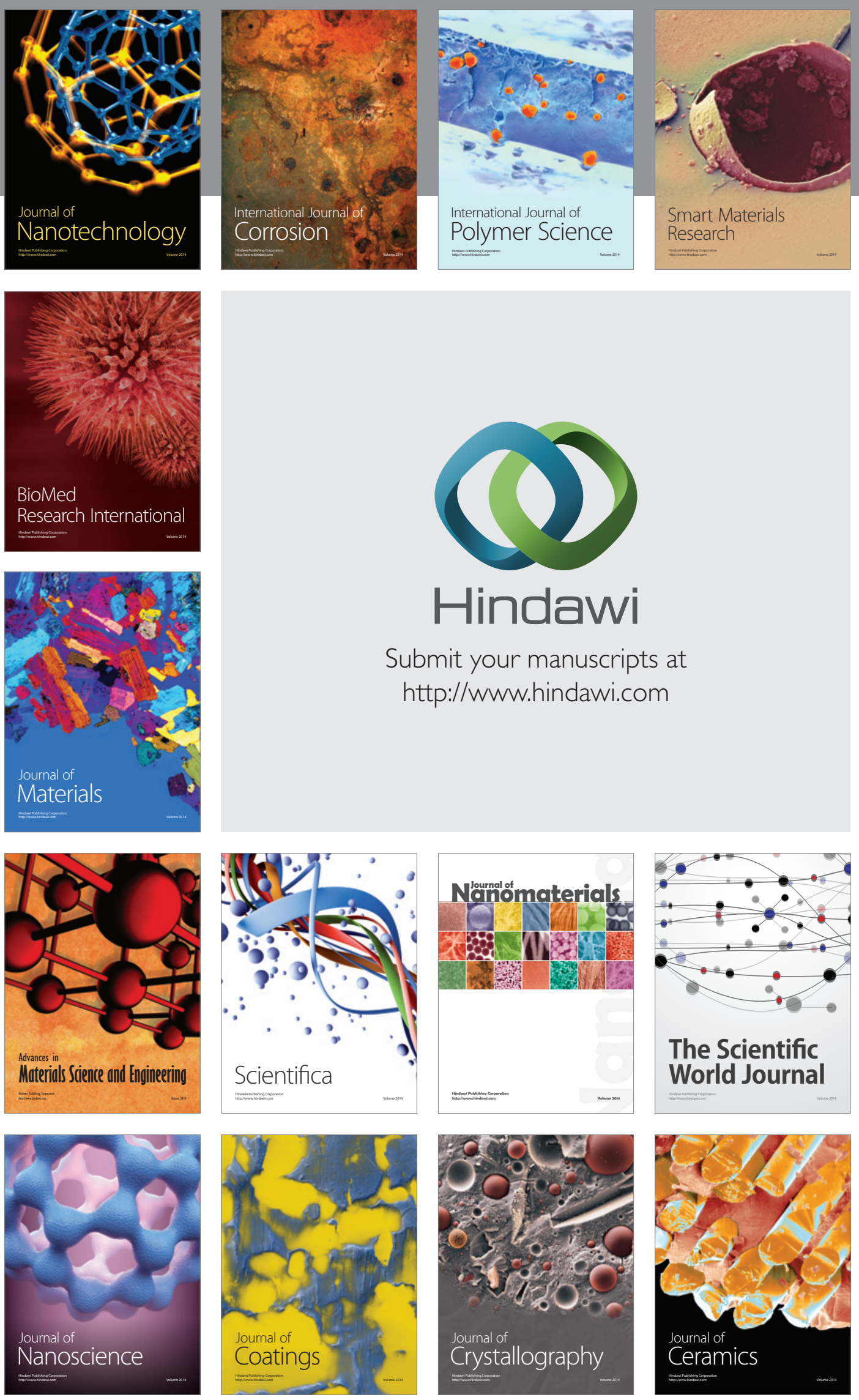

The Scientific World Journal

Submit your manuscripts at

http://www.hindawi.com

\section{World Journal}

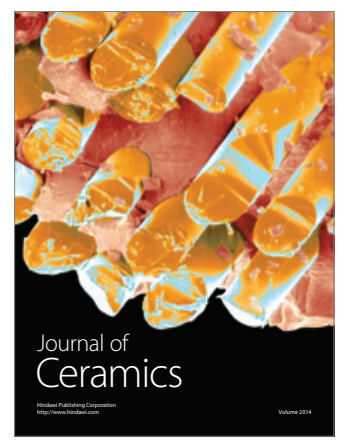

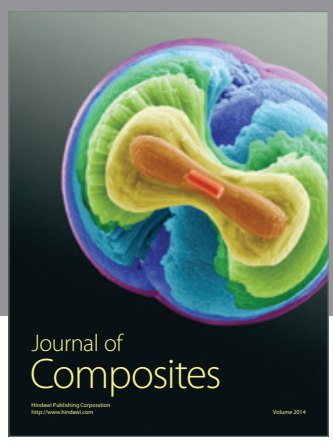
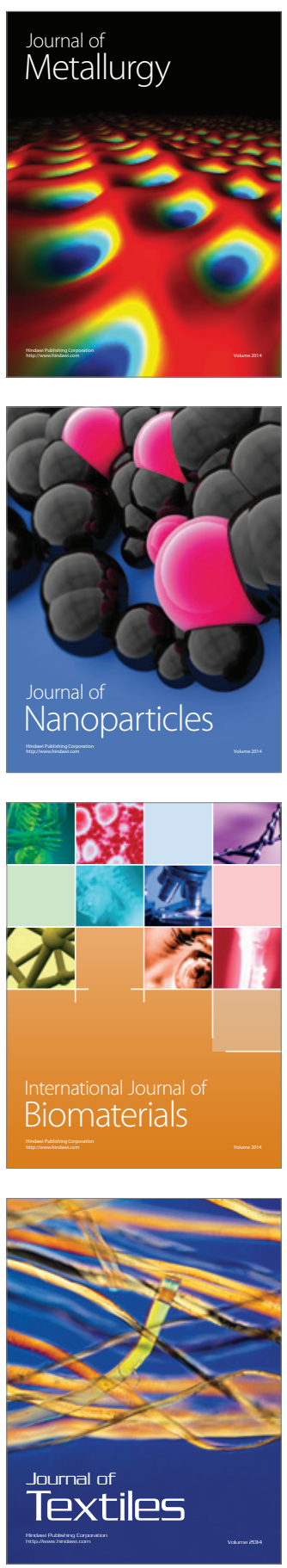